\title{
Factors behind Buying Intentions of Social Media Users in Pakistan
}

\author{
Naveeda Sangi*, Liu Shuguang, Prince Abdul Samad \\ Ocean University of China, Qingdao, Shandong, China. \\ * Corresponding author. Tel.: 008615966801667; email: naveeda021990@yahoo.com \\ Manuscript submitted February 23, 2017; accepted May 16, 2017. \\ doi: 10.17706/ijeeee.2017.7.3.153-167
}

\begin{abstract}
This Study focuses on the factors influencing buyers' intentions indulged in S-commerce in Pakistan. We empirically analyzed factors influencing buyer's intentions on social media focusing Facebook in developing countries like Pakistan. Using the basic components of TPB (Theory of Planned Behavior), we integrated No. of Likes and Comments and Suggested Posts of Facebook in basic antecedents of social norms i.e. Friends and Family as the main factors in influencing buying intentions of Facebook buyers. We also integrated Smartphones usage as an important influencing factor. With the help of econometric computer software IBM SPSS, we statistically analyzed the data collected through surveys. The results of this study show that two factors leave a great impact on buying intentions i.e. Family and Use of Smartphones. Other findings of this study underlines that Facebook is preferred for the shopping purpose as compared to websites. Majority of Buyers like to make purchases at least once a month. Females are actively involved in S-commerce in Pakistan as compared to Males. Witnessing statistical results, we conclude that using social media especially Facebook is a beneficial way for SMEs to develop as the buyers are actively involved. Revealing the answers to the core questions an SME usually encounter before entering market available on social media, this study is equally important for the business communities of Pakistan as well as China.
\end{abstract}

Key words: Buying intentions, social commerce, smartphones, small medium enterprises.

\section{Introduction}

At present, shifting traditional business to E-commerce is an emerging trend in developing countries. [1] indicates that e-commerce has been acknowledged by the developing countries to be significant for the economic growth. The progression of internet has made the e-commerce to develop faster. The countries where internet penetration rate is low are also on the go of adopting E-commerce for developing business. Although e-commerce have many benefits for the organizations in the developing countries but the small and medium enterprises deals with many hurdles in adopting e-commerce when compared to the larger organizations. Researchers emphasize that the common barriers for SMEs in the developing countries to adopt e-commerce include internal factors [2] such as awareness, lack of expertise and cost, as well as external factors such as IT infrastructure and Government [3]. Similarly various internal and external barriers of e-commerce adoption are faced by the SMEs in Pakistan. On the contrary these barriers are successfully being roofed by the creation of S-Commerce (Social Commerce). The trend of social commerce in Pakistan is establishing due to two main reasons:

1) Rapid diffusion of PDAs specially Smartphones.

2) Availability of free-of-cost Social Media platform through Internet.org i.e. Facebook. 
Literature indicates that limited diffusion of technologies such as computers, hurdles the adoption of E-commerce by the SMEs [4]. But recently the rapid diffusion of sophisticated form of mini-computer i.e. smartphones is successfully overcoming this hurdle. $80 \%$ of the total population in Pakistan owns a mobile phone. According to PTA (Pakistan Telecommunications Authority) 50\% of mobile phone users own a smartphone and $40 \%$ still deals with the featured phone. Additionally recent launch of Internet.org has allowed millions of Pakistanis to access famous SNS (Social Networking Site) i.e. Facebook (FB) free of any costs. After the successful launch of Internet.org in Pakistan users of Facebook have dramatically increased. Having nearly 3 billion of users currently (Internetworldstat.com), Facebook has become the most popular site that has been used in Pakistan so far. Countless entrepreneurs have started their small household businesses through creating pages on Facebook. SMEs (Small and Medium Enterprises) possess a valuable consideration in the economic growth. [5] believes that the countries which plan to become more active in growing their economy must emphasize the importance of SMEs. Share of SMEs in GDP of the developed as well as developing countries is moderately substantial. According to SMEDA Pakistan (Small and Medium Enterprise Development Authority), at this time the share of SMEs in the national GDP is significant comprising of approximately $40 \%$ in the total GDP of the country. Due to the entire economic crisis Pakistan is currently facing, every sector has been negatively affected including SMEs. Therefore SMEs in Pakistan are seriously striving hard to seek sustainable ways to develop their business growth. In this situation, use of social media to get indulged in S-commerce is highly beneficial for the SMEs in Pakistan to develop their business. But before getting indulge in S-Commerce, SMEs encounter many questions such as:

1) Is there enough market available on the social media?

2) What kind of market is readily available to become the potential buyers?

3) Are these potential buyers temporarily available?

Our study intends to answer all the above questions through a survey-based study, in order to provide a piece of valuable information to the SMEs of Pakistan. Due to the rise of social media adoption, past studies have highlighted various important phenomenon considered by businesses approaching social media as a powerful business tool. Such as [6] has proposed a model for businesses to follow in order to build positive brand image through using social media. We attempt to analyze the factors behind buying intention of buyers in Pakistan using social media particularly Facebook for shopping. The purpose of this research is to explore and analyze the factors affecting the buying intentions of customers in Pakistan while getting engaged in S-commerce. Therefore, the objectives of this study are threefold:

1) Identifying an apparent biography of the customers involved in S-commerce in Pakistan.

2) Assessing the factors behind the buying intentions of social media users indulged in S-Commerce.

3) To highlight the importance of S-commerce as a sustainable platform for the growth of SMEs.

Facebook, being the famous SNS in Pakistan has gained much attention by marketers, sellers and buyers recently. People not only use Facebook as a medium of Connectivity, Entertainment or staying Social but use it for shopping purpose as well. Apart from the famous large enterprises, small medium enterprises have also drawn their attention in creating Facebook Pages as an S-Commerce tool for their business growth. More people are reachable and targeted through Facebook via audience insights. Although there are many other supportive tools on Facebook to grow the business but a business is a failure if there is no market. The intention of buyers is an important tool to predict the future purchases. Buyers are the main players in any market. If there are no buyers, there is no market. The previous researchers have focused on the buying intentions and behaviors of customers involved in E-commerce in Pakistan. The factors influencing buyers' intentions and behaviors in S-commerce have not gained much attention so far. Therefore using TPB (Theory of Planned Behavior), this study highlights the factors that have robust influence on buying intentions of customers involved in S-commerce. [7] has described TPB as an advantageous framework that 
is conceptualized to deal with the intention of human social behavior in context with attitudes, subjective norms and perceived control. This study attempts to re-conceptualize the original concept of TPB in order to analyze the buying intentions of the users of Facebook in Pakistan. Over the decades, TPB has been widely used by the researchers as a valid tool for assessing the purchase/buying intentions as well as the buying behaviors.

In the past studies, researchers have re-conceptualized or extended this theory according to the requirement of their research purpose. For Example [8] extended the TPB in order to describe and forecast the E-commerce adoption. [9] presented TPB with two additional variables i.e. perceived consequences and perceived innovativeness in order to test the effect of consumer intentions in internet buying behavior. Some researchers have combined the idea of TPB with some other variables. Such as, [10] has used TPB in addition with E-WOM (Electronic Word of Mouth), network embeddedness and website quality control to explore antecedents of intention that lead involvement in online-group buying. In this study, we adopt only one component from the original theory of planned behaviors i.e. Social Norms including influence of Family, Friends, No. of "Likes and Comments" (i.e. E-WOM) and Suggested posts (E-Advertisement). Previous studies have not paid much attention to the impact of technology diffusion in the buying intentions or behaviors, therefore to fill this gap in the literature one of the important variables added in the proposed research model is Smartphone Usage. Smartphone diffusion is astoundingly rapid not only in Pakistan but in the rest of world as well. Therefore we believe that similarly like all the other factors, Smartphone adoption is also an important component that should be studied as a core influencing factor behind the buying intentions in social media usage for shopping.

\section{Literature Review}

Ref. [11] discusses the use of social media carried out by the SMEs in the developing countries for the sake of their business development. In the developing countries many of the SMEs are using social media for their business success. Facebook has been widely studied as an important tool for small businesses through the both sellers as well as the buyers' perspective. Ref. [12] indicates that SMEs use the famous SNS Facebook to market their products and reach out their targeted customers. Ref. [13] articulate that the SMEs which are using Facebook as a business tool have experienced a better competitive advantage. Many books are also being published recently, in order to provide some guidelines to fabricate the businesses by using Facebook and other social medias. Such as [14] has wrote down The ultimate guide to use Facebook to do free or cheap marketing effectively and make tons of money with your business. Ref. [15] presented his ideas about leveraging Facebook's features for marketing campaigns. Ref. [16] has highlighted the usefulness of social medias, online videos, mobile applications, blogs, news release and viral marketing to reach out customers directly.

Ref. [17] performed a survey-based research to analyze the impact of a recently launched app by Facebook named as "ThingBook", showing that the impact of social opinions (specially from friends) matters a lot in buyers' decision making process. Ref. [18] has used Grey Incidence Analysis to show the positive impact of promotion campaigns on the buyers' decision making. Ref. [19] has introduced a model that highlights the factors (PR-Perceived Risk, TR-Trust, SN-Subjective Norm, POSE-Past Online Shopping Experience) affecting buyers purchase intentions in S-commerce (Facebook). Ref. [20] also believes that trust and risk factors are the main factors in E-commerce especially in S-commerce. Using SP (Social presence) theory [21] assess that the buying intentions of customers are affected by the nature of social aspects in trust beliefs. E-commerce is not new in Pakistan. It has been adopted and studied since couple of years. In Pakistan, studies regarding E-commerce have continually being carried out since a decade. Ref. [22] in their study have shown that the trust factor is the main factor in E-commerce that hold backs customers 
to continue shopping online. Ref. [23] proposed 6 important factors (PU-Perceived Usefulness, PR-Perceived Risk, PE-Perceived Enjoyment, PEOU-Perceived Ease of Use, DT-Distrust and LF-Legal Framework) that possess a great influence on the online buying intentions of Pakistani buyers. In another study [24] articulates that women in Pakistan are more obsessed with online shopping as compared to the men, as they find it entertaining and secure to make purchases online. Ref. [25] concluded in their study that two factors i.e. trust and convenience has a stronger impact on the online buying behavior as compared to other factors i.e. time, product variety and privacy. Ref. [26] discovers that the online buying behavior is affected by E-WOM and brand image.

\section{Theoretical Model and Hypothesis Development}

Taking the literature review in account, the components of the theoretical model are studied in-depth to ensure their validity of inclusion in this study. All the components of the model are extracted from the previous studies that are already been acknowledged and considered as meaningful variables in the literature that influence the buying behaviors and intentions.

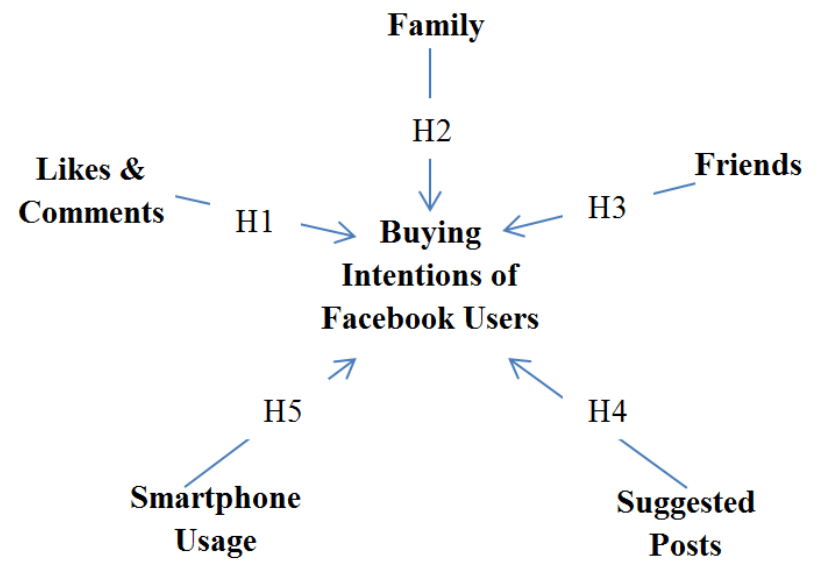

Fig 1. Theoretical model.

\subsection{Subjective Norms}

Facebook "LIKES" is a considerable factor to be studied by many researchers that drive the buying urge/ behavior [27]. Facebook "LIKES and COMMENTS" are one of the powerful Users' generated content. Ref. [28] emphasize that user generated content has as economic value. The "LIKE" button in the past was reflected to be of less significance for the news websites and thus "RECOMEND" button was preferred [29]. The continual up gradation of Facebook is undoubtedly opening up more ways for the online traders to explore the user generated feedback of their targeted customers. The users' consumer experience becomes more enjoyable and effective by the feasibility of executing media features [30]. Recently updated version of "LIKE" button by Facebook has given a more feasible and varied way of expression to the users. Users can express their feelings by choosing a specified expression through the "LIKE" button. This "LIKE" button includes 4 extended expressions i.e. Love, Haha (happiness, funny), Wow (amazed, astonished etc.), Sad and Angry. Apart from "Likes", "Comments" from the experienced buyers have a significant impact on buyers' intentions who intend to make a purchase on an SNS.

"Comment" feature in Facebook is more expressing. The liking and replying the comment is even much expressive. Ref. [31] has concluded that the Facebook user's buying behavior is affected by two factors i.e. 1Positive Likes and 2- Positive comments. Taking the literature review in consideration, this study added the "Likes" and "Comments" as an important component in TPB to analyses the buying intention of customers 
on Facebook in Pakistan.

H1: No. of "LIKES" \& "COMMENTS" have a positive impact on Buying Intentions of FB users.

As the main consideration of this study is a social platform i.e. Facebook, thus we adopt the "Subjective Norms" from TPB as a main component of our research model. The component "Subjective Norms" has been referred as the social influence in both theories TRA proposed by [32] as well as TPB proposed by [33]. Sociality affects the buying behavior to a much greater extent. This idea has been applied and proven by many researchers in the past. [34] have revealed in their study that compulsive buying behavior is influenced by social motivation (i.e. offer distinctiveness and number of sold out coupons). [35] refers the Social influence as the main factor that influences the purchase intention. In the research model developed in this study; the authors have included three antecedents that collectively support the component of "Social Norms". First antecedent is the impact of family i.e. Parents, Siblings, Spouse, Kids etc. [31]. The second antecedent of the "Subjective Norms" is the friends on Facebook as they are an important source of information thus they have the potential to affect the buying decisions of users of various SNS. Influence of social motivation is also studied while assessing the behavior of buyers in Pakistan. [36] has named social motivation factors as collectivism in his study. The study shows that collectivism has a stronger relationship with impulsive buying behavior as compared to the other variable i.e. individualism. The third antecedent is "Suggested Posts" that has been replaced with media in the "Subjective Norms". Suggested post in Facebook is a special advertising tool that allows marketers to reach their target market more easily. It acts like the traditional advertisement on the traditional media, which appears time to time on user's news feed. Advertisement has a positive impact on the buying behavior [37]. All three antecedents of Subjective norms are linked directly to the Buying Intentions in this study and regarded as main components of TPB. The authors believe that each of the three components has a considerable influence exclusively.

H2: Family has a positive impact on Buying Intentions of FB users.

H3: Friends have a positive impact on Buying Intentions of FB users.

H4: "Suggested Posts" have a positive impact on Buying Intentions of FB users.

\subsection{Smartphones}

The last construct of the proposed re-conceptualized model of this study is the Smartphones adoption. Internet supported advanced technologies such as PDAs (Personal Digital Assistants) are shifting the traditional way of buying towards the digital way of buying. Use of PDAs specifically Smartphones has been indulged in our daily life activities especially while trading. The adoption of innovative trending technology has made the buyers much smarter overall the world. One of the most affordable and easy-to-use PDA is Smartphone. There have been a number of studies in the past that have used smartphones as a key influencing variable in order to analyze the buying behaviors. While buying a product in stores, Turkish buyers use their smartphones to search information, read online reviews, check availability in nearest stores, compare prices and consult sales representative or personal contacts. During the search process the customers often buy from online stores as well [38]. Smartphones are unique in online commerce, which allows consumers to get engaged in real-time price comparisons regardless of geographical distances [39]. Convenience factor is too high in online purchasing that the number of in-store purchases is reducing day by day. Customers have started avoiding the exhausting nature of traditional shopping and have diverted their attention to online buying. Therefore the owners of physical stores are making their best to connect their in-store shopping with technology relating with mobile phones [40].

The use of smartphones in online shopping is growing extensively than any other mode of online buying. Ref. [41] mentions that Smartphone Usage allows users to access all the relevant information available on the social media. The increased use of smartphones is due to the fact that the smartphones are used as mini PCs (Personal Computers). With each new model of smartphone, a new exciting perk is delivered to the end 
user, which substitutes the features of PCs. Smartphone is the precious gadget of users that sticks to them 24/7. Making purchases online using the all-time digital companion is easy to manage as the smartphone is operated continuously throughout the routine life. Due to this fact the duration between the orders made online using mobile devices is less as compared to the duration between the orders made online through PCs [42].

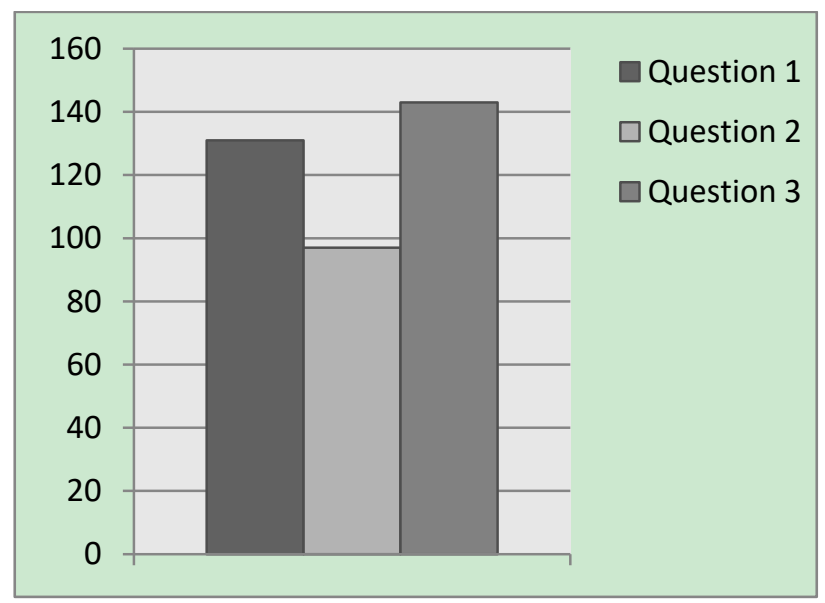

Fig 2. Pre-test statistics.

Table 1. Pre-test Questions

\begin{tabular}{ll}
\hline \hline Questions & Description \\
\hline 1 & Do you use FB (Facebook) through Smartphone? \\
2 & Did you made an FB account after becoming a smartphone user? \\
3 & Would you prefer using FB through Smartphone in future? \\
\hline
\end{tabular}

Table 2. Demographics

\begin{tabular}{ll}
\hline \hline Category & Percentage \\
\hline Age & \\
\hline Under 18 & 4 \\
$18-20$ & 10 \\
$21-23$ & 9 \\
$24-26$ & 38 \\
$27-30$ & 27 \\
Above 30 & 12 \\
\hline Gender & \\
\hline Male & 21 \\
Female & 79 \\
\hline Education & \\
\hline Under Graduate & 14 \\
Bachelors & 48 \\
Masters & 36 \\
M.phill & 1 \\
Ph.D & 1 \\
\hline Location & \\
\hline Balochistan & 8 \\
Khyber Pakhtunkhuwa & 11 \\
Punjab & 49 \\
Sindh & 32 \\
\hline Facebook Buyers & \\
\hline Buyers & 95 \\
Non Buyers & 5 \\
\hline \hline
\end{tabular}


Facebook in Pakistan has been accessed through Smartphones largely. Apart from the literature a pre-experiment survey was performed to recognize if smartphone is a valid component to measure the buying intentions of Pakistani Facebook users. The survey was simply designed based on three questions and was sent to the Facebook users randomly through Facebook Messenger.

The statistics for the responses is shown in Fig. 2.

The results of pre-test survey have shown that there is consistent relationship among smartphones and FB usage. Out of 150 respondents 131 (87.3 \%) FB users access their FB account through smartphone. 97 (64.6\%) of the respondents made an FB account after they adopted a smartphone. 143 (95.3\%) respondents admit that they will pursue using FB only through a smartphone due to its convenience.

Beholding the results, it is quite obvious that smartphone compliments FB, thus we consider it as a strong influencing factor in our theoretical model.

H5: Smartphone usage has a positive impact on the Buying Intentions of FB users.

\section{Research Methodology}

This study is survey-based. Facebook was chosen to select the sample because of various reasons. Firstly, it is the most famous SNS currently being used in Pakistan. Secondly, FB provides a healthy platform for shopping. And most importantly, due to the launch of Internet.org FB in Pakistan is preferably used and therefore an increase in the sales has been witnessed by e-traders.

\subsection{Selection of Sample and Data Collection}

The data was collected through a questionnaire that was sent to 450 Facebook users across Pakistan. The authors kept a keen eye on the famous Facebook pages relating with selling of products. After observing for 3 months, the authors selected 450 active buyers who were spotted to be the regular respondents to the posts of the observed pages. The questionnaire was sent to the subjects through Facebook Messenger. From the targeted sample size 389 subjects responded. After cutting off the number of incomplete responses from the gathered questionnaires, we finally get a sample size of 320 complete questionnaires. Table 2 shows the demographics of the sample size comprising of 320 respondents.

The data for our study was extracted from questionnaire comprising of two sections. The questions in the first part were designed to extract some details of the buyers so that the questions drawn in this study could be well-answered. The additional information is illustrated in Figures below.

Fig. 3 shows the purchasing frequency of the buyers on Facebook. 9\% of the total respondents shop on Facebook at least once a week. 19\% of the respondents shop on Facebook at least twice a week. 54\% buyers shop at least once a month whereas remaining $20 \%$ buyers shop twice a month regularly. Most of the studied subjects routinely buy products from Facebook page at least once in a month. Figure 4 shows the statistics of devices preferably used by buyers while shopping on Facebook pages. The results indicate that Smartphones are the most widely used devices having $93 \%$ of the respondents using only smartphones for shopping in S-commerce. $27 \%$ buyers use smartphones as well as laptops. $19 \%$ of the buyers switch to 3 devices while buying i.e. tablet or smartphone or laptop. Only $2 \%$ used a desktop.

\subsection{Validity of Constructs}

The second section of the questionnaire enclosed 34 items collectively. All the statements in this section were related with the components of the research model. Five points Likert Scale was used to allow the subject to respond about the statements, which was ranging from 1 to 5 , where 1 represented "Strongly Disagree" and 5 represented "Strongly Agree".

The validity/ reliability of all the 34 items were assessed through calculating the most popular reliability statistics i.e. Cronbach's Alpha, which is used to assess dichotomous or multi-point formatted question [43]. 
Researchers emphasize that while using Likert scale it is important to calculate internal consistency through Cronbach's Alpha [44].

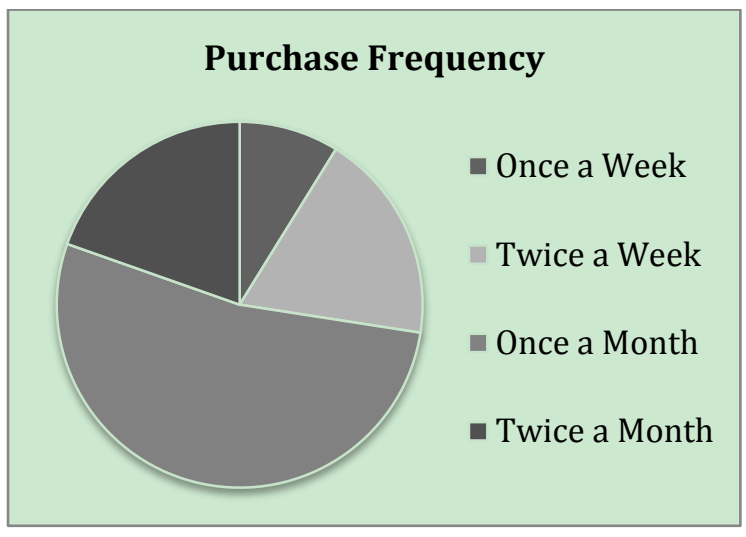

Fig. 3. Purchasing frequency.

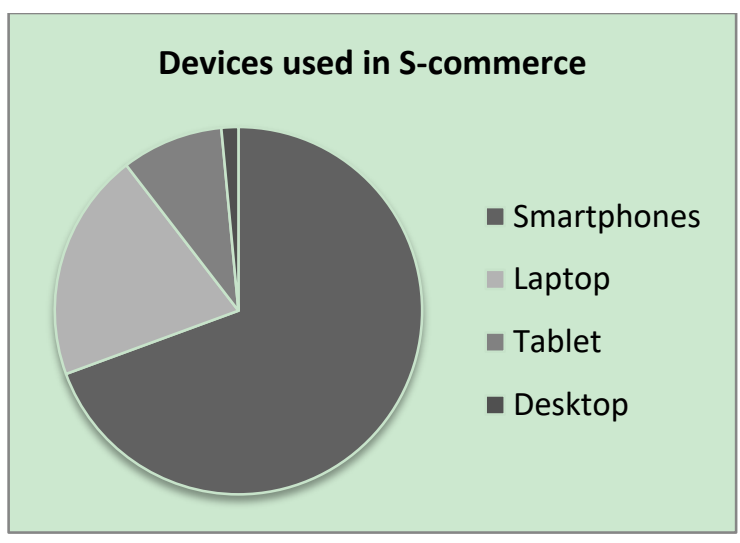

Fig. 4. Devices used by buyers.

Table 4. Reliability of the Constructs

\begin{tabular}{lcc}
\hline Variables & Indicators & Cronbach's Alpha \\
\hline Likes \& Comments & L\&C1 & .909 \\
& L\&C2 & \\
& L\&C3 & \\
& L\&C4 & \\
& L\&C5 & .784 \\
& L\&66 & \\
\hline Family & Fam1 & .921 \\
& Fam2 & \\
\hline Friends & Fam3 & \\
& Fri1 & \\
\hline Suggested Posts & Fri2 & \\
& Fri3 & \\
& SP1 & \\
& SP2 & \\
Smartphones Usage & SP3 & \\
& SP4 & \\
& SP5 & \\
& SU1 & \\
& SU2 & \\
& SU3 & \\
& SU4 & \\
\hline
\end{tabular}


Table 3 displays the Cronbach's alpha of each construct that is higher than $70 \%$, showing the reliability of inclusion of all the constructs in this study.

\subsection{Data Analysis}

The authors choose step-wise linear regression to analyze the variables that influence the purchase intentions of FB users. Regression has been widely used by the researchers in analyzing purchase intentions/ behaviors through ТPB [45].

Step-wise linear regression is preferred for this study because of the following reasons:

- It is a method of regressing multiple variables while simultaneously excluding those that are not important.

- Removing the weakest variables the stepwise linear regression explains the distribution best.

The variables chosen in this study are diverged from each other, for that reason we believe that step-wise linear regression is an authentic method to analyze the significant variables. We used IBM SPSS software to perform our statistical test. The collected data was based on Likert scale, thus it was more feasible to use SPSS than any other software to analyze our data. Other methods did not proved to be significant in analyzing our model.

\section{Results}

Table 4.1 shows the descriptive statistics. 291 responses were selected out of 320 subjects. The reason behind cutting off the responses was to refine the results based on the respondents who buy from FB through Smartphones exclusively.

Table 4.2 displays the significant variables that influence the buying intentions of FB users the most. These two variables are Family and No. of smartphone users. Family being the most influential variable stands at the first rank, whereas as No. of Smartphones users ranks second. Other 3 variables were excluded i.e. No. of Likes and Comments, Friends and Suggested posts.

In Table 4.3 we can see the beta coefficients value for both models. Considering the result we construct the equation for Buying Intentions of FB users in Pakistan as:

$$
\begin{gathered}
\text { Buying Intentions of FB users }= \\
\text { Constant }+ \text { Family }+ \text { No. of Smartphones users } \\
\text { Buying Intentions }=-.135+.630+.413
\end{gathered}
$$

The prediction equation shows that 1 unit change in Family brought .630 units change in Buying Intention. Similarly 1 unit change in No. of Smartphones users brought .413 units change in Buying Intention. Consistent with the significance of the results two hypothesis of this study were supported consequently, the other three were rejected. Table 4.4 shows the hypothesis grades of all the variables tested in this study.

Table 4.1. Descriptive Statistics

\begin{tabular}{|l|c|r|r|}
\hline \hline \multicolumn{4}{c}{ Descriptive Statistics } \\
\hline \multicolumn{1}{|c|}{} & \multicolumn{1}{c}{ Mean } & Std. Deviation & \multicolumn{1}{c|}{ } \\
\hline Buying Intentions on FB & 2.8832 & .85506 & 291 \\
No. Of Likes and & 4.1478 & 1.00455 & 291 \\
Comments & & & \\
No.of Smartphones users & 4.1443 & .95039 & 291 \\
Family & 2.0722 & 1.24497 & 291 \\
Friends & 4.3505 & .86353 & 291 \\
Suggested Posts & 4.1787 & .81517 & 291 \\
\hline \hline
\end{tabular}

The Excluded variables and their statistics are shown in Table 4.5. The No. of Likes and Comments has a 
significant impact on the Buying Intentions in the first model whereas in the second model it turns insignificant. Considering the drastic move in the significance we assume that No. of Likes and Comments somehow has a positive impact on the Buying Intentions of FB users or it is neutrally significant. Thus we predict this variable as Neutral in this study. Suggested posts have no big difference in both models. This shows that this variable has no influence on the buying intentions of FB users. Friends also have a high $\mathrm{p}$ value that makes it insignificant.

Table 4.2. Variables Entered/Removed

\begin{tabular}{|c|c|c|c|}
\hline \multicolumn{4}{|c|}{ Variables Entered/Removed ${ }^{\Xi}$} \\
\hline Model & $\begin{array}{l}\text { Variables } \\
\text { Entered }\end{array}$ & $\begin{array}{l}\text { Variables } \\
\text { Removed }\end{array}$ & Method \\
\hline 1 & Family & & $\begin{array}{l}\text { Stepwise } \\
\text { (Criteria: } \\
\text { Probability-of- } \\
\text { F-to-enter } \Leftarrow= \\
050 \text {. } \\
\text { Probability-of- } \\
\text { F-to-remove } \\
>=.100 \text { ). }\end{array}$ \\
\hline 2 & $\begin{array}{l}\text { No.of } \\
\text { Smartphones } \\
\text { users }\end{array}$ & & $\begin{array}{l}\text { Stepwise } \\
\text { (Criteria: } \\
\text { Probability-of- } \\
\text { F-to-enter }<= \\
050 \text {. } \\
\text { Probability-of- } \\
\text { F-to-remove } \\
>=.100 \text { ). }\end{array}$ \\
\hline
\end{tabular}

Table 4.3. Coefficients

\begin{tabular}{|c|c|c|c|c|c|c|}
\hline \multicolumn{7}{|c|}{ Coefficients $^{a}$} \\
\hline \multirow{2}{*}{\multicolumn{2}{|c|}{ Model }} & \multicolumn{2}{|c|}{ Unstandardized Coefficients } & \multirow{2}{*}{$\begin{array}{c}\begin{array}{c}\text { Standardized } \\
\text { Coefficients }\end{array} \\
\text { Beta }\end{array}$} & \multirow[b]{2}{*}{$t$} & \multirow[b]{2}{*}{ Sig. } \\
\hline & & $\mathrm{B}$ & Std. Error & & & \\
\hline \multirow[t]{2}{*}{1} & (Constant) & 2.194 & .085 & & 25.687 & .000 \\
\hline & Family & .332 & .035 & .484 & 9.406 & .000 \\
\hline \multirow[t]{3}{*}{2} & (Constant) & -.135 & .767 & & -.176 & .860 \\
\hline & Family & .630 & .103 & .917 & 6.092 & .000 \\
\hline & No.of Smartphones users & .413 & .135 & 460 & 3.054 & .002 \\
\hline
\end{tabular}

Table 4.4 Hypothesis

\begin{tabular}{ll}
\hline \hline \multicolumn{1}{c}{ Model } & \multicolumn{1}{c}{ Hypothesis } \\
\hline No. of Likes and comments & H1 Neutral \\
Family & H2 Supported \\
Friends & H3 Rejected \\
Suggested posts & H4 Rejected \\
No. of Smartphone users & H5 Supported \\
\hline \hline
\end{tabular}

Table 4.5 Excluded Variables

\begin{tabular}{|c|c|c|c|c|c|c|}
\hline \multicolumn{7}{|c|}{ Excluded Variables $^{\circ}$} \\
\hline \multirow{2}{*}{\multicolumn{2}{|c|}{ Model }} & \multirow[b]{2}{*}{ Beta In } & \multirow[b]{2}{*}{$\mathrm{t}$} & \multirow[b]{2}{*}{ Sig. } & \multirow{2}{*}{$\begin{array}{c}\text { Partial } \\
\text { Correlation }\end{array}$} & \multirow{2}{*}{$\begin{array}{c}\text { Collinearity } \\
\text { Statistics }\end{array}$} \\
\hline & & & & & & \\
\hline 1 & $\begin{array}{l}\text { No. Of Likes and } \\
\text { comments }\end{array}$ & $.328^{a}$ & 2.368 & .019 & .138 & .136 \\
\hline & No.of Smartphones users & $.460^{a}$ & 3.054 & .002 & .177 & .114 \\
\hline & Friends & $.105^{a}$ & .762 & .446 & .045 & .139 \\
\hline & Suggested Posts & $-.029^{a}$ & -.388 & .698 & -.023 & .490 \\
\hline 2 & $\begin{array}{l}\text { No. Of Likes and } \\
\text { Comments }\end{array}$ & & & .430 & & .092 \\
\hline & Friends & $.004^{\mathrm{b}}$ & .026 & .979 & .002 & .130 \\
\hline & Suggested Posts & $-.031^{b}$ & -.428 & .669 & -.025 & .490 \\
\hline
\end{tabular}




\section{Discussions, Implications and Limitations}

This study investigated the factors that affect the buying intentions of Pakistani buyers indulged in S-commerce through accessing famous SNS Facebook. The purpose of this study was to answer the main questions that an SME may encounter before entering the market available on the social media. S-commerce is a favorable platform for SMEs to grow. In Pakistan due to scarce resources, the options for developing businesses are limited. Economic crisis like poverty and inflation along with other major issues such as electricity shortfalls hinders new as well as existing SMEs to develop. In this situation, availability of cost effective platforms such as social networking sites are an easy way out for the businesses to grow consistently. Cheaper prices of electronic gadgets have provided customers an affordable, time saving and faster mode of shopping online. Although, Pakistan is still facing a poor internet infrastructure of broadband and of third and fourth generation internet but free access to Facebook provided by internet.org has facilitated the availability to buyers as well as sellers to indulge in S-commerce. Thus it is important to study the scope of S-commerce activities on Facebook in Pakistan. The SMEs can make an effective use of this emerging trend of S-commerce. Online shopping has been abundantly acknowledged by sellers, buyers and researchers in Pakistan. Consequently, this study elaborates the buyers' perspective focusing on which factors influence their intentions to buy products available on SNS. Identifying the buyers' interests is a beneficial tool for SMEs to assess their pursuance in S-commerce. The two significant factors that have been discovered in this study are ever increasing. Smartphone adoption is still at its growing stage in Pakistan, and has a considerable potential to grow faster. The influence of family is also long lasting as Pakistan is a country that cares about the relations. Pakistan is a country that values its ethics and morals. Family has stayed an important factor in Pakistan that possesses a great influence in almost all the decisions. Similarly our study has shown that Family is impactful in manipulating the buying intentions of customers in S-commerce as well. Among all the variables, impact of smartphone usage is most considerable influencing factor in buying intentions not only for the buyers available on the social media in Pakistan but in the rest of the world as well. With each passing day smartphones are getting linked with every economic activity worldwide and therefore significantly compliments online buying. For Example, it acts as a mode of payment that is most important for E-commerce/S-commerce, searching information, accessing social media instantly etc. The SMEs have numerous chances to operate their business by making most out of this emerging trend of S-commerce. Through S-commerce SMEs can be developed that will ultimately contribute to the country's economy as a whole. Additionally the benefits of this study are not only useful for the SMEs in Pakistan but in China as well. The project of CPEC (China Pakistan Economic Corridor) has embraced a new market for Chinese business tycoons. The findings of this study therefore provide valuable information about the intentions of Pakistani buyers' on social media to the Chinese business community as well.

The limitations of this study cannot be ignored. Firstly, the sample size is considerably small. Secondly the constructed model can be modified by adding more variables that affect the buying intentions in S-commerce. Thirdly, this study is focused only on one SNS i.e. Facebook whereas there is a huge opportunity for other researchers to overcome this limitation and consider other famous SNS as well.

\section{Conclusion}

Internet growth has facilitated the scope of E-commerce and S-commerce in developing countries. In Pakistan, the extensive use of SNS especially Facebook has triggered start-ups of a considerable number of private businesses through creating pages on FB. Similarly, several SMEs are also operating via FB. This study attempts to provide a brief scenario of the factors that influence the buying intentions and the biography of the customers available on FB in Pakistan. Along with traditional Social factors i.e. Family and Friends, we integrated two additional social factors that take place on the social media which are "no. of 
Likes and Comments" (E-WOM) and "Suggested posts" (alternate of traditional media or advertisement). The other core influencing factor studied in this study was "Smartphone usage". Using the step-wise linear regression through a computer software IBM SPSS this study shows that two factors that are No. of smartphones and Family has a positive impact on the buying intentions of Facebook users in Pakistan. The non-impactful variables included No. of Likes and Comments, Friends and Suggested posts. According to the statistical results of this analysis, the authors conclude that the buying intentions are closely inter-linked with No. of Smartphone users and impact of the Family. Both influencing variables are long lasting and growing thus, the authors forecast that the scope of S-commerce in Pakistan have extensive potential to grow. Therefore, SMEs in Pakistan should pay a serious attention to grow their business through the famous social networking platform i.e. Facebook. The study also shows that females are more actively involved in S-commerce as compared to Male buyers. Most of the observed subjects prefer to buy products from FB rather than any website. There are very less users who avoid making any purchase through Facebook. Other findings of this study are listed as follows:

- The people residing in Punjab and Sindh are more likely to buy from FB pages.

- Only 5\% of the sample size did not made any purchase from FB.

- The regular buyers usually make purchases at least once a month.

- $93 \%$ of the sample size uses their Smartphone while making a purchase from FB.

- $81 \%$ of the respondents believe that Smartphone is the easiest mode amongst other alternative PDAs to be used in S-commerce.

\section{References}

[1] Zaied, A. N. H. (2012). Barriers to e-commerce adoption in Egyptian SMEs. International Journal of Information Engineering and Electronic Business, 4(3), 9.

[2] Cloete, E., Courtney, S., \& Fintz, J. (2002). Small businesses' acceptance and adoption of e-commerce in the Western Cape Province of South Africa. The Electronic Journal of Information Systems in Developing Countries, 10.

[3] El-Nawawy, M. A., \& Ismail, M. M. (1999). Overcoming deterrents and impediments to electronic commerce in light of globalisation: The case of Egypt. Proceedings of 9th Annual Conference of the Internet Society, INET (vol. 99).

[4] Kapurubandara, M., \& Lawson, R. (2006). Barriers to adopting ICT and e-commerce with SMEs in developing countries: An exploratory study in Sri Lanka. University of Western Sydney, Australia, 2005-2016.

[5] Mishra, M. M. R. (2016). SME's: A booster of India's economic growth. International Journal of Multifaceted and Multilingual Studies, 3(3).

[6] Dib, H., \& Alhaddad, A. A. (2015). Determinants of brand image in social media. International Journal of e-Education, e-Business, e-Management and e-Learning, 5(4), 180.

[7] Ajzen, I. (1991). The theory of planned behavior. Organizational Behavior and Human Decision Processes, 50(2), 179-211.

[8] Pavlou, P. A., \& Fygenson, M. (2006). Understanding and predicting electronic commerce adoption: An extension of the theory of planned behavior. MIS Quarterly, 115-143.

[9] Limayem, M., Khalifa, M., \& Frini, A. (2000). What makes consumers buy from Internet? A longitudinal study of online shopping. IEEE Transactions on Systems, Man, and Cybernetics-Part A: Systems and Humans, 30(4), 421-432.

[10] Cheng, H. H., \& Huang, S. W. (2013). Exploring antecedents and consequence of online group-buying intention: An extended perspective on theory of planned behavior. International Journal of Information 
Management, 33(1), 185-198.

[11] Schaupp, L. C., \& Bélanger, F. (2016). Social commerce benefits for small businesses: An organizational level study. Journal of Organizational and End User Computing (JOEUC), 28(3), 49-66.

[12] Khan, M. L. (2013). Small business use of facebook for marketing: The case of a family owned Mediterranean restaurant. Available at SSRN 2579508.

[13] Augar, N., \& Zeleznikow, J. (2013). I just saw this on Facebook, I need it now': exploring small business use of Facebook. Proceedings of 24th Australasian Conference on Information Systems (ACIS) (pp. 1-11). RMIT University.

[14] Campbell, D. (2015). Facebook: Facebook marketing the ultimate guide to use facebook to do free or cheap marketing effectively and make tons of money with your business.

[15] Carter, B., Levy, J., \& Levy, J. R. (2012). Facebook marketing: Leveraging Facebook's features for your marketing campaigns. Que Publishing.

[16] Scott, D. M. (2015). The new rules of marketing and PR: How to use social media, online video, mobile applications, blogs, news releases, and viral marketing to reach buyers directly. John Wiley \& Sons.

[17] Cvijikj, I. P., Cetin, G., Karpischek, S., \& Michahelles, F. (2016). Influence of Facebook on Purchase Decision Making.

[18] Orzan, G., Delcea, C., Ioanas, E., \& Orzan, M. C. (2015). Buyers' decisions in online social networks environment. Journal of Eastern Europe Research in Business \& Economics.

[19] Leeraphong, A., \& Mardjo, A. (2013). Trust and risk in purchase intention through online social network: A focus group study of facebook in Thailand. Journal of Economics, Business and Management, 1(4), 314-318.

[20] Esmaeili, L., Mutallebi, M., Mardani, S., \& Golpayegani, S. A. H. (2015). Studying the affecting factors on trust in social commerce. arXiv preprint arXiv:1508.04048.

[21] Lu, B., Fan, W., \& Zhou, M. (2016). Social presence, trust, and social commerce purchase intention: An empirical research. Computers in Human Behavior, 56, 225-237.

[22] Sulaiman, A., Mohezar, S., \& Rasheed, A. (2007). A trust model for e-commerce in Pakistan: An empirical research. Asian Journal of Information Technology, 6(2), 192-199.

[23] Akhlaq, A., \& Ahmed, E. (2015). Digital commerce in emerging economies: Factors associated with online shopping intentions in Pakistan. International Journal of Emerging Markets, 10(4), 634-647.

[24] Akhlaq, A., \& Ahmed, E. (2016). Gender differences among online shopping factors in Pakistan. Organizations and Markets in Emerging Economies, 7(1).

[25] Dost, M. K. B., Illyas, M., \& Rehman, C. A. (2015). Online shopping trends and its effects on consumer buying behavior: A Case study of young generation of Pakistan. Journal of Social Development, 5(1).

[26] Kazmi, A., \& Mehmood, Q. (2016). The effect of electronic word of mouth communication and brand image on purchase intention: A case of consumer electronics in Haripur, Pakistan. Management Science Letters, 6(7), 499-508.

[27] Chen, J. V., Su, B. C., \& Widjaja, A. E. (2016). Facebook C2C social commerce: A study of online impulse buying. Decision Support Systems, 83, 57-69.

[28] Hajli, N., \& Sims, J. (2015). Social commerce: The transfer of power from sellers to buyers. Technological Forecasting and Social Change, 94, 350-358.

[29] Hille, S., \& Bakker, P. (2013). I like news. Searching for the 'Holy Grail'of social media: The use of Facebook by Dutch news media and their audiences. European Journal of Communication, 28(6), 663-680.

[30] Koli, A., Chowdhury, A., \& Dhar, D. (2016). Requirement of new media features for enhancing online shopping experience of smartphone users. Intelligent Systems Technologies and Applications (pp. 
423-435). Springer International Publishing.

[31] Nguyen, N. L., \& Ai-Zhong, H. E. (2016). The ages, genders, positive comments, and likes as predictors of facebook users' buying intention: An insight into the difference of age and gender. Imperial Journal of Interdisciplinary Research, 2(2), 242-253.

[32] Fishbein, M., \& Ajzen, I. (1975). Belief, Attitude, Intention and Behavior: An Introduction to Theory and Research. Reading, MA: Addison-Wesley.

[33] Ajzen, I. (1985). From intentions to actions: A theory of planned behavior. Action Control (pp. 11-39). Springer Berlin Heidelberg.

[34] Kukar-Kinney, M., Scheinbaum, A. C., \& Schaefers, T. (2016). Compulsive buying in online daily deal settings: An investigation of motivations and contextual elements. Journal of Business Research, 69(2), 691-699.

[35] Gunawan, D. D., \& Huarng, K. H. (2015). Viral effects of social network and media on consumers' purchase intention. Journal of Business Research, 68(11), 2237-2241.

[36] Jalees, T. (2009). An empirical analysis of impulsive buying behavior in Pakistan. International Review of Business Research Papers, 5(6), 298-308.

[37] Malik, M. E., Ghafoor, M. M., Iqbal, H. K., Ali, Q., Hunbal, H., Noman, M., \& Ahmad, B. (2013). Impact of brand image and advertisement on consumer buying behavior. World Applied Sciences Journal, 23(1), 117-122.

[38] Nasır, S., \& Kurtuluş, B. (2016). Technology is transforming shopping behavior: In-store mobile technology usage. Handbook of Research on Consumerism and Buying Behavior in Developing Nations (pp. 168-189). IGI Global.

[39] Li, I., Simonson, R., Babajanova, G., \& Tuomala, M. (2016). Smartphone diffusion and consumer price comparison shopping behavior: Implications for the marketplace fairness act. Economics Bulletin, 36(3), 1337-1353.

[40] Liao, T. H. Enhancing in-store shopping experience for smartphone users.

[41] Mahajan, R. (2015). Use of social media as a new investigative tool in marketing research for small business. International Journal of e-Education, e-Business, e-Management and e-Learning, 5(3), 129.

[42] Wang, R. J. H., Malthouse, E. C., \& Krishnamurthi, L. (2016). How vmobile shopping affects customer purchase behaior: A retailer's perspective. Let's Get Engaged! Crossing the Threshold of Marketing's Engagement Era (pp. 703-704). Springer International Publishing.

[43] Santos, J. R. A. (1999). Cronbach's alpha: A tool for assessing the reliability of scales. Journal of Extension, 37(2), 1-5.

[44] Gliem, J. A., \& Gliem, R. R. (2003). Calculating, interpreting, and reporting Cronbach's alpha reliability coefficient for Likert-type scales. Midwest Research-to-Practice Conference in Adult, Continuing, and Community Education.

[45] Shah, A. S., \& Mohamed, S. N. (2011). Applying the theory of planned behavior (TPB) in halal food purchasing. International Journal of Commerce and Management, 21(1), 8-20.

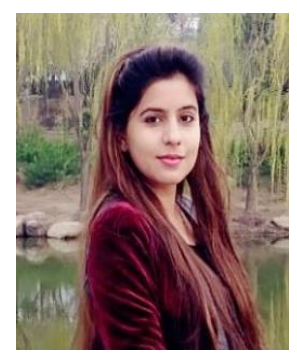

Naveeda Sangi is Pakistani national and was born in Sukkur, Sindh, Pakistan on 27-07-1990. She is a student of Ph.D. in Ocean University of China and is currently residing in Qingdao, Shandong China. Her research focuses on the role of technologies in the economy. She received her Master's and Bachelor's degree in Business Administration from University of Sindh, Jamshoro, Sindh, Pakistan. She has worked as a feasibility analyst in a private trading company of Pakistan and has served many institutes as a teacher. 


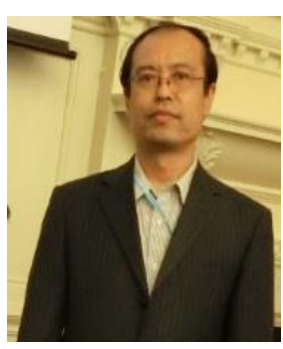

Liu Shuguang is a professor, Ph.D. tutor and deputy director in College of Economics, Ocean University of China. His research interests include world regional economies and Asian geo-economic cooperation, marine spatial economics and urban and regional planning. He has previously served in Department of Geography, Taishan College as a lecturer and director of Regional Geography Education / Research Group. He has also served as Dean Assistant (2006-2010) in College of Economics, Ocean University of China.

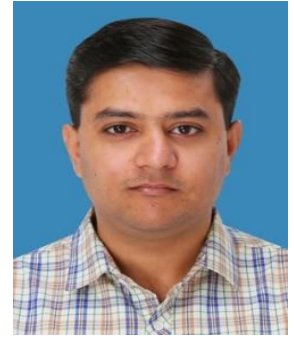

Prince Abdul Samad is a Pakistani national, currently serving in China State Construction and Engineering Corporation Limited as a procurement officer. $\mathrm{He}$ received his master's degree in international business from Ocean University of China in 2015. His research interests include building social commerce platform between Pakistan and China. He has also done basic Chinese language course from Beijing University of Aeronautics and Astronautics (Beihang), Beijing, P.R. China in 2013. 